\title{
Can the Fed Talk the Hind Legs Off the Stock Market?*
}

\author{
Sylvester Eijffinger, ${ }^{\mathrm{a}}$ Ronald Mahieu, ${ }^{\mathrm{b}}$ and Louis Raes ${ }^{\mathrm{c}}$ \\ ${ }^{a}$ CentER and European Banking Center, Tilburg University, CEPR \\ ${ }^{\mathrm{b}}$ CentER and Netspar \\ ${ }^{c}$ CentER and European Banking Center, Tilburg University
}

This paper analyzes the impact of U.S. central bank communication on individual stock returns. We find a strong conditional effect of communication on stocks. The response of equities to central bank talk depends critically on the business cycle. In bad times, monetary policy communication inducing an upward revision of the path of future policy is good news for stocks. During an expansion, the effect is weaker and on average negative. The impact of central bank communication on stock prices displays similar cross-sectional variation as central bank actions. Cyclical industries are found to be more sensitive to central bank communication. We find that the stock prices of firms which have low cash flows, low returns to assets or equity, very high or low debt levels, small size, or which use more trade credit are affected more by central bank communication. Our evidence suggests that central bank communication by the Federal Open Market Committee has an impact on stocks and provides additional evidence for the demand and the credit channel.

JEL Codes: G14, E44, E52, E58.

${ }^{*}$ We thank Jakob de Haan, Jose Faias, Refet Gürkaynak, David-Jan Jansen, Vincent van Kervel, Alexandros Kontonikas, Pierre Lafourcade, Bertrand Melenberg, Damjan Pfajfar, Peter Schotman, Wolf Wagner, and seminar participants at the Columbia Graduate School of Business Ph.D. seminar, De Nederlandsche Bank, the Paris December 2011 Finance meeting, the Prebem 2011 conference, the European Monetary Forum 2012 meeting, and seminars at Tilburg University for comments, discussions, and e-mails. Author e-mail (Raes): l.b.d.raes@uvt.nl. 


\section{Introduction}

What impact does central bank communication have on the stock market? Does the impact of central bank communication vary in the cross-section and over time? What are the determinants of such variation?

The impact of monetary policy on the stock market is a topic of wide interest. Policymakers, academics, and market participants would like to know the consequences of particular interventions on stock prices. While the impact of central bank actions (e.g., lowering the interest rate) on stock returns has been extensively studied, the impact of central bank communication on asset prices has received far less attention in the literature. In this paper, we demonstrate that considering individual stocks instead of indices and accounting for the business cycle does lead to substantial effects from central bank communication to individual stock prices.

As discussed in detail by Woodford (2005), theory suggests that the path of expected short-term rates in the future is crucial for the economic decisions that a central bank may wish to influence. In this view, even in the absence of central bank communication, the fact that monetary policy actions (surprise moves in the policy rate) are able to move markets can be attributed to the implications of the forward path of interest rates. If the path of future short-term interest rates is so important, central banks may as well try to influence expectations by communicating to the markets and the general public. This is the idea of forward guidance, i.e., the central bank communicates in order to manage expectations of future short-term interest rates. Over the decade, this idea has become increasingly popular among policymakers.

In this paper, we study the impact of communication by the Federal Open Market Committee (FOMC) on stocks in the S\&P 500. As such, this paper complements a string of papers which focused on the impact of central bank actions on the stock market. At the same time, our results add to the body of research examining the potence of forward guidance, a topic for which there is renewed interest in the current debate on monetary policy at the zero lower bound; see Woodford (2012) 1

\footnotetext{
${ }^{1}$ The reader may wish to consult the excellent literature reviews by Blinder et al. (2008) and Blinder (2009). This body of research considers the potential
} 
We contribute to the literature in several ways. First, we account for the state of the economy by allowing for different effects of central bank communication depending on particular phases of the business cycle. The finance literature shows that there may be considerable state dependence in the response to news in the stock market. Boyd, $\mathrm{Hu}$, and Jagannathan (2005) show that on average an announcement of rising unemployment is good news for stocks during expansions and bad news during economic contractions. We find that Federal Reserve communication implying an upward revision of the path of future policy is perceived as good news during recessions, whereas the effect is negative (and much weaker) in an expansion. We expect stocks to respond to monetary policy communication when two conditions are met. First, the monetary policymaker is deemed to be credible. Second, market participants attribute superior forecasting performance to the Federal Reserve.

If a central bank is perceived to be a better forecaster and has sufficient credibility, then market participants may update their views with the information provided by central banks. Communication suggesting a future policy tightening could be positive news for the stock market if stock market participants interpret this as signaling a positive outlook. The intuition is that the Federal Reserve, with its dual mandate, would be very reluctant to raise the policy rate unless there were clear signs of economic recovery 2

Our second contribution is that we provide a detailed and systematic analysis of the response of the stock market to central bank communication. To that end, we consider the response of individual stocks. This approach allows us to consider firm and industry effects. This is of interest because the literature on the credit channel of monetary policy transmission predicts asymmetric responses of firms to a tightening of monetary policy. A firm with severe credit constraints

benefits (drawbacks) of central bank communication, its practical implementation, and the effectiveness of such communication near the zero lower bound. A succinct article on forward guidance as a policy instrument is Bernanke and Reinhart (2004).

${ }^{2}$ The credibility of the Federal Reserve as a central bank is commonly accepted; see de Haan, Eijffinger, and Waller (2005, pp. 122-23). Evidence for the (attributed) superior forecasting performance of the Federal Reserve is given by Romer and Romer (2000). Andersson, Dillén, and Sellin (2006) find that financial markets react to information on the outlook that central banks provide. 
will find it harder to access credit when interest rates go up. This may constrain their operational activities, jeopardizing their profits and pushing stock prices downwards. However, the demand for a firm's goods may also be affected. The interest rate channel suggests that firms facing a highly cyclical or interest-sensitive demand should be more responsive to monetary policy; see Ehrmann and Fratzscher (2004). Therefore, we also expect variation in responses to monetary policy across industry affiliations. Insofar that financial markets are forward looking, we expect the industry effects of central bank communication to be similar to the industry effects of central bank actions. If financial market participants are convinced by a monetary policy announcement and they revise their expectations accordingly, then the same channels should be active. Our results confirm that indeed the cyclical industries are more responsive to central bank communication 3

A few studies have considered the effect of central bank communication on the stock market. An influential study is the paper by Gürkaynak, Sack, and Swanson (2005). In this paper, the authors introduced a methodology to consider the effects of central bank communication. The paper focused on the impact on interest rates and a composite stock market index. They found that central bank communication did not matter for the aggregate stock market, whereas it may exert a large influence on interest rates. Wongswan (2009), Ammer, Vega, and Wongswan (2010), and Hausman and Wongswan (2011) investigate the link between U.S. monetary policy and foreign assets. In line with Gürkaynak, Sack, and Swanson (2005), their results indicate that central bank communication does not affect equities substantially, while it does influence interest rates and exchange rates. In contrast, surprise changes in the federal funds rate (central bank actions) matter a great deal for foreign equities. The recent paper by Lucca and Moench (2015) differs from the previously cited studies in that it documents unconditional excess returns ahead of FOMC meetings (see Lucca and Moench 2015,

\footnotetext{
${ }^{3}$ In the case of monetary policy actions Ehrmann and Fratzscher (2004), Bernanke and Kuttner (2005), Basistha and Kurov (2008), Kurov (2010), and Laeven and Tong (2012) consider industry effects. Most of these studies use a crude breakdown of industries. Firm effects are considered by Thorbecke (1997), Perez-Quiros and Timmermann (2000), and Ehrmann and Fratzscher (2004).
} 
p. 4). The authors see their results as complementary to the literature documenting conditional responses of various asset classes, including stocks, to macroeconomic news announcements in general. Their results point to the influence of anticipation rather than the realization of policy announcements and decisions.

Besides the study of Federal Reserve communication, authors have also investigated the communication strategies of other central banks and their effects. Brand, Buncic, and Turunen (2010) consider the effects of European Central Bank communication on interest rates; Karagedikli and Siklos (2008) study the effects of verbal statements by the central bank of New Zealand on exchange rates. The literature on the effects of central bank communication has predominantly focused on interest rates. Some authors have focused on the effects of central bank communication on other assets, such as commodities, on credit default swap (CDS) spreads, or on exchange rates 4 As mentioned above, papers focusing on central bank communication and the stock market tend to find small or no responses in the stock market. In this paper, we demonstrate that considering individual stocks instead of indices and accounting for the business cycle does lead to substantial effects from central bank communication to individual stock prices. Moreover, these responses are in line with theoretical predictions.

There are two leading empirical approaches to investigating the link between monetary policy and the stock market. Some studies investigate responses of stocks to shocks derived from an identified vector autoregression. Examples of this approach are Thorbecke (1997) and, more recently, D'Amico and Farka (2011), who improved on earlier work by proposing a new identification strategy with the use of high-frequency data. The other approach, known as the event-study approach, is more popular, and our paper fits into this strand of the literature. Notable early contributions are Ehrmann and Fratzscher (2004) and Bernanke and Kuttner (2005)

\footnotetext{
${ }^{4}$ Hayo, Kutan, and Neuenkirch (2012) consider the effects of central bank communication on commodity price volatility and Fender, Hayo, and Neuenkirch (2011) on CDS spreads. Four studies on central bank communication and exchange rates are Jansen and de Haan (2005, 2007) and Fratzscher (2008a, 2008b).
} 
and, more recently, Ammer, Vega, and Wongswan (2010), Hausman and Wongswan (2011), and Laeven and Tong (2012).

This chapter proceeds as follows. In section 2 , we present the event-study approach and discuss our data. In section 3, we present some benchmark results, which we elaborate on in a section on industry effects (section 4) and a section on firm effects (section 5). After discussing the empirical evidence, we discuss the robustness of our results in sections 6 and 7 . In section 8 , we conclude.

\section{The Event-Study Approach}

The event-study approach to investigating the response of financial markets to monetary policy dates back to a study by Cook and Hahn (1989). In their study the authors regressed changes in market interest rates on changes in the federal funds rate for a sample of seventy-five days on which the Federal Reserve changed the federal funds rate.

But markets are forward looking. If a change in the federal funds rate is entirely anticipated, we expect this change to be incorporated into market interest rates already. If the policy action is correctly priced in advance, the action itself should have no effect on asset prices 5

Therefore we need a way to extract the unexpected part of the change. A way to do this was put forward by Kuttner (2001), who showed how to extract monetary policy surprises from federal funds futures data. With these surprise measures (unexpected monetary policy interventions), many studies subsequently estimated regressions of the following form 6

$$
\Delta y_{t}=\alpha+\beta \text { Surprise }_{t}+\epsilon_{t}
$$

\footnotetext{
${ }^{5}$ This intuitive prediction is confirmed in Bernanke and Kuttner (2005, p. 1226).

${ }^{6}$ In this paper, we use federal funds futures and Eurodollar futures. Other financial contracts can also be used, as in Cochrane and Piazzesi (2002) or Rigobon and Sack (2004). Our choice follows the recommendations by Gürkaynak, Sack, and Swanson (2007) and is the most common choice in the literature.
} 
where $\Delta y_{t}$ is the change in an asset price, such as a stock index, individual stocks, investment portfolios, or market interest rates measured over an interval that includes the monetary policy announcement. Subsequently, Gürkaynak, Sack, and Swanson (2005) extended this one-factor approach by formally testing whether the variation in short-term interest rates on FOMC dates is characterized by one or more factors. Their results provided strong evidence for a twofactor approach. Two factors are able to capture movements in asset prices due to monetary policy, whereas one factor misses a large part of the monetary-policy-induced variation. The current federal funds rate target factor reflects the surprise associated with a change in the federal funds rate target (or lack thereof). The future path of policy factor is closely associated with FOMC statements and reflects the influence the FOMC exerts on market expectations through its communication strategy. 7 We will pursue the two-factor approach in this paper. In the remainder of this study, we refer to these factors as the target (factor) and the path (factor) 8

\subsection{Sample Choice and Data Sources}

In this paper, we use a sample of events starting with the FOMC meeting of February 1994. From that meeting onwards, the Federal Reserve started issuing a press release after every FOMC meeting and change in policy 9

\footnotetext{
${ }^{7}$ The narrative in this paper hinges on the assumption that the path factor really captures communication. Extensive evidence for this is provided in Gürkaynak, Sack, and Swanson (2005).

${ }^{8}$ Gürkaynak, Sack, and Swanson (2005) tested for the required number of factors using the matrix rank test of Cragg and Donald (1997). Subsequently, they constructed the two factors from the first two principal components of a set of short-term interest rates with suitable scaling and rotation to allow for a structural interpretation. Following up on Gürkaynak, Sack, and Swanson (2005), studies now routinely use these two factors, e.g., Ammer, Vega, and Wongswan (2010) and Hausman and Wongswan (2011).

${ }^{9}$ Most event studies focusing on FOMC meetings start their sample in 1994, e.g., Ehrmann and Fratzscher (2004), Rigobon and Sack (2004), and Hausman and Wongswan (2011). A related argument is provided by D'Amico and Farka (2011), who write: "We begin our sample in 1994, because the FOMC . . began explicitly announcing its target for the federal funds rate at that time, and, thus, there is a potential structural break in financial market forecasting performance beginning at that date." For more details, see section 1.2 in Gürkaynak, Sack, and Swanson (2005).
} 
Since 1994, a number of changes in the communication practices of the FOMC took place 10 Several authors argue that these have enhanced its transparency and credibility; see Swanson (2006), Yellen (2006), and Kwan (2007). One innovation in communication practices seems especially influential - the inclusion of forwardlooking language. Kwan (2007) stresses that these forward-looking statements have significantly improved market participants' understanding of near-term monetary policy. For this reason, while we focus throughout the paper on a sample starting in February 1994 and ending in 2009, we also report estimated coefficients for a sample starting after June 2003 to give a feel for the differences in estimated effects when considering a different data sample 11

The events we consider in this paper are all FOMC meetings, both scheduled and unscheduled, starting in February 1994 and ending in December 2009. We have omitted the unscheduled FOMC meeting after the terrorist attacks of September 11, 2001, as is customary in the literature. This results in 144 FOMC meetings for which the dates can be found on the web page of the Federal Reserve 12

For each meeting, we use the companies that were in the S\&P 500 at that time. Throughout this paper, we focus on daily stock returns. Higher-frequency data has the advantage of allowing for more precise estimates and a better model fit because less confounding news is captured. However, at a lower frequency, we can focus on longerrun effects and we do not capture overshooting effects that quickly disappear; see Ehrmann and Fratzscher (2004). By comparing the results from different frequencies, authors have found that, for daily

\footnotetext{
${ }^{10}$ These changes are, respectively, the inclusion of a balance of risks in the press release (in 2000), the addition of individual votes and preferred policy choices of FOMC members (in 2002), the introduction of forward-looking language (in 2003), and the release of the minutes of a meeting with three weeks' delay (in 2004). In April 2011, the FOMC held a press conference after its meeting for the first time.

${ }^{11}$ We have investigated alternative sample periods motivated by changes in communication practices, but the conclusions presented in this paper remain by and large the same.

${ }^{12}$ Our list of event dates follows the list of meetings provided in the appendix of Gürkaynak, Sack, and Swanson (2005), which we extended with the FOMC meetings mentioned on http://www.federalreserve.gov/monetarypolicy/ fomccalendars.htm.
} 
intervals, endogeneity and simultaneity problems are not an issue. Studies investigating this in some detail are Gürkaynak, Sack, and Swanson (2005) and D'Amico and Farka (2011).

The stock data used in this paper were obtained from the CRSP (Center for Research in Security Prices) database and were combined with accounting data obtained from the Compustat database. For one robustness check, we construct returns from intraday data obtained from the Trade and Quote (TAQ) database. Furthermore, we use macroeconomic data obtained from the Federal Reserve Board and National Bureau of Economic Research (NBER) recession indicators. The data on federal funds futures and Eurodollar futures were obtained from the CME Group. The construction of the target and path surprises follows our description in subsection 2.2. Further details on the data construction can be found in the online appendix to this paper, available at http://www.ijcb.org.

\subsection{Market-Based Surprise Measures of Monetary Policy}

Federal funds futures have a value at expiration of 100 minus the average federal funds rate over the expiration month. Consider the value of such a contract on the day before an FOMC meeting taking place at time $t$. Denote with $r_{-1}$ the federal funds rate before the meeting and with $r_{0}$ the federal funds rate prevailing after the meeting. The no-arbitrage condition demands that the implied spot rate $\mathrm{ff}^{0}$ on such a futures contract before the meeting would be the following:

$$
\mathrm{ff}_{t-t}^{0}=\frac{d_{0}}{D_{0}} r_{-1}+\frac{D_{0}-d_{0}}{D_{0}} \mathbb{E}_{t-t}\left(r_{0}\right)+\mu_{t-t}^{0} .
$$

Here $D_{0}$ indicates the number of days that the month we consider contains, and $d_{0}$ indicates how many days have elapsed before the FOMC meeting takes place. This equation states that the implied spot rate on the contract $\mathrm{ff}_{t-t}^{0}$ (just before the meeting) equals a weighted average of the prevailing interest rate $r_{-1}$ and the interest rate which is expected to prevail after the FOMC meeting $\mathbb{E}_{t-t}\left(r_{0}\right)$ plus a risk premium $\mu_{t-t}^{0}$. After the policy decision is known, the implied rate is the following:

$$
\mathrm{ff}_{t}^{0}=\frac{d_{0}}{D_{0}} r_{-1}+\frac{D_{0}-d_{0}}{D_{0}} r_{0}+\mu_{t}^{0},
$$


that is, the weighted average of both interest rates plus a risk premium. Using the two equations above, we can construct the unanticipated component of the monetary policy action:

$$
\begin{aligned}
\text { Surprise }_{t} \equiv & r_{0}-\mathbb{E}_{t-t}\left(r_{0}\right) \\
= & {\left[\mathrm{ff}_{t}^{0}-\frac{d_{0}}{D_{0}} r_{-1}-\mu_{t}^{0}\right] \frac{D_{0}}{D_{0}-d_{0}} } \\
& -\left[\mathrm{ff}_{t-t}^{0}-\frac{d_{0}}{D_{0}} r_{-1}-\mu_{t-t}^{0}\right] \frac{D_{0}}{D_{0}-d_{0}} \\
= & {\left[\left(\mathrm{ff}_{t}^{0}-\mathrm{ff}_{t-t}^{0}\right)+\left(\frac{d_{0}}{D_{0}} r_{-1}-\frac{d_{0}}{D_{0}} r_{-1}\right)-\left(\mu_{t}^{0}-\mu_{t-t}^{0}\right)\right] } \\
& \times \frac{D_{0}}{D_{0}-d_{0}} \\
\cong & {\left[\mathrm{ft}_{t}^{0}-\mathrm{ff}_{t-t}^{0}\right] \frac{D_{0}}{D_{0}-d_{0}} . }
\end{aligned}
$$

We arrive at the final line by assuming that high-frequency changes in the risk premium are negligible, or $\mu_{t}^{0}-\mu_{t-t}^{0} \cong 0$. Evidence for this assumption was provided by Piazzesi and Swanson (2008) 13 The scaling factor $\frac{D_{0}}{D_{0}-d_{0}}$ blows up the change in the term premium at the end of the month, causing measurement-error concerns. To alleviate these concerns, we switch to the contract that expires in the next month when the scaling factor is larger than four.

We define the path factor as the change in the four-quartersahead Eurodollar interest rate futures orthogonal to the target

\footnotetext{
${ }^{13}$ Another concern might be that the contracts we use are not liquid enough or that the contracts do not capture expectations of the future course of monetary policy for another reason. The study by Gürkaynak, Sack, and Swanson (2007) compares a wide range of alternative financial instruments (term federal funds loans, federal funds futures, term Eurodollar deposits, Eurodollar futures, Treasury bills, and commercial paper) with differing liquidity and risk characteristics. The authors provide an in-depth analysis and recommend federal funds futures for short horizons up to six months and Eurodollar futures, term Eurodollars, or term federal funds for horizons from six months to one year. We follow their advice and use federal funds futures for the construction of the target surprise and Eurodollar futures for the path surprise. The latter choice is also in line with the bulk of the literature following the two-factor approach.
} 
surprise. So the path surprise equals the residual term $\epsilon_{t}$ in the following regression:

$$
\Delta \text { Eurodollar future }_{4 Q, t}=\alpha+\beta \text { Target } \text { Surprise }_{t}+\epsilon_{t},
$$

where the regressor Target Surprise $_{t}$ is the surprise measure we constructed in equation (4). The four-quarters-ahead Eurodollar futures is assumed to capture the markets' expectations of the policy path for the coming year. The regression above allows for a simple decomposition in a target factor and a residual path factor. This residual path factor corresponds to all news that moves futures rates for the upcoming year on FOMC meeting days without changing the current federal funds rate. This factor should be interpreted as the news that market participants have learned from the FOMC's statement about the expected future path of monetary policy besides what they have learned about the level of the target rate 14

In figure 1, we have plotted the target and the path factor. The figure shows that the path factor varies throughout the entire sample, whereas the target factor shows much less variation after the introduction of forward-looking statements. Target surprises became smaller because the forward-looking statements had the purpose of guiding market participants and the Federal Reserve seemed successful, at least during expansions. We also see that large values (in absolute value) of both factors tend to occur mainly during recessions (the shaded areas).

To appreciate the path factor, we discuss here some of the largest observations (in absolute value) of our sample in detail. If the path factor is well constructed, it should pick up major "newsworthy" communication by the FOMC. The three largest observations are given in table 1.

Our path factor takes its the largest value on September 29, 2008. This day represents a milestone in U.S. financial history. During the night of the 28th to the 29th, the leaders of Senate and House

\footnotetext{
${ }^{14}$ The construction of factors above differs from Gürkaynak, Sack, and Swanson (2005) but is more straightforward and easier to understand. The approach outlined in the text was put forward in Wongswan (2009) and Hausman and Wongswan (2011). Unreported regressions using the (more complex but essentially equivalent) construction of factors from Gürkaynak, Sack, and Swanson (2005) confirmed that both approaches yield very similar results.
} 


\section{Figure 1. Target and Path Surprises}

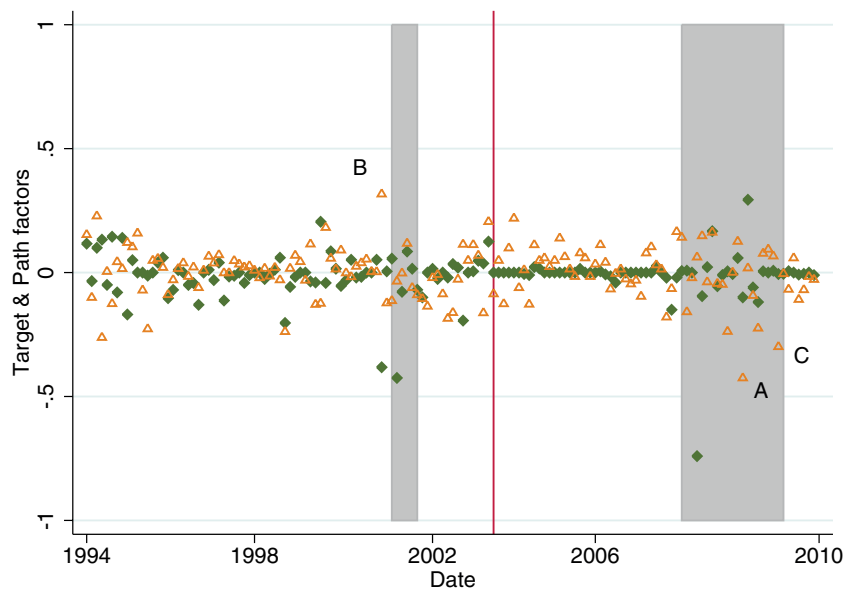

Notes: This figure shows a plot of the target surprises (solid diamonds) and path surprises (hollow triangles). The shaded areas depict periods marked as a recession by the NBER turning points, which is from March until November 2001 and from December 2007 until June 2009. The vertical line serves as a demarcation line to split the sample into two parts: before and after the introduction of forward-looking statements.

\section{Table 1. Target and Path Factor on Selected Dates}

\begin{tabular}{|l|c|c|c|}
\hline & Date & Target Factor & Path Factor \\
\hline A & September 29, 2008 & -0.1 & -0.43 \\
B & January 3, 2001 & -0.38 & 0.32 \\
C & March 18, 2009 & -0.01 & -0.3 \\
\hline
\end{tabular}

Note: This table reports the values for the target and path factor, respectively, for the three meetings with the largest path factor (in absolute value).

announced a tentative deal allowing the government purchase of mortgage-backed securities. On the same day, the Dow Jones Industrial Average experienced the largest drop in its history. On this day, the Federal Reserve announced "several initiatives to support financial stability and to maintain a stable flow of credit to the 
economy during this period of significant strain in global markets 15 The initiatives consisted of Term Auction Facility auctions as well as increasing swap authorization limits - an intervention taken in coordination with other major central banks (the European Central Bank, Bank of England, Bank of Canada, and Bank of Japan).

The second largest value is found for January 3, 2001. On this day the FOMC caused a big surprise by cutting the discount rate. This reportedly caused financial markets to temper the probability of a recession and was considered to lessen the need for easing at a later date 16

The third largest value is found for March 18, 2009. This date represents another milestone in the history of unconventional monetary policy at the Federal Reserve. The third paragraph of the press release stated:17 "In these circumstances, the Federal Reserve will employ all available tools to promote economic recovery and to preserve price stability." This kicked off the first round of quantitative easing where 1.25 trillion USD mortgage-backed securities were purchased, as well as 200 billion USD in agency debt and 300 billion USD in long-term Treasury securities. Each of these three meetings and the related press releases received considerable media attention. These events had a major impact on financial markets, and it is clear that what the FOMC communicated to the markets was considered to be major news.

Another way to understand the target and path factor is to consider the impact they have on medium- and long-term interest rates. In table 2, we present the results of two regressions. The first two columns show the results of a regression with only the target factor as an explanatory variable, and the second two columns show the results when we add the path factor. The table shows that the path factor is important for medium- and long-term yields and the impact is larger at the long end. For ten-year Treasury notes, we find that the target factor has negligible explanatory power, whereas the path factor matters substantially. These results mimic the findings

\footnotetext{
${ }^{15}$ See http://www.federalreserve.gov/newsevents/press/monetary/20080929a. htm.

${ }^{16}$ See also Gürkaynak, Sack, and Swanson (2005), where this is labeled as ahead of the curve.

${ }^{17}$ See http://www.federalreserve.gov/newsevents/press/monetary/20090318a. htm.
} 
Table 2. Response of Interest Rates

\begin{tabular}{|l|c|c|c|c|}
\hline & $\begin{array}{c}\text { One-Year } \\
\text { Note }\end{array}$ & $\begin{array}{c}\text { Ten-Year } \\
\text { Note }\end{array}$ & $\begin{array}{c}\text { One-Year } \\
\text { Note }\end{array}$ & $\begin{array}{c}\text { Ten-Year } \\
\text { Note }\end{array}$ \\
\hline Target & $\begin{array}{c}0.42^{* * *} \\
(8.52)\end{array}$ & $\begin{array}{c}0.08 \\
(1.24)\end{array}$ & $\begin{array}{c}0.42^{* * *} \\
(13.00) \\
0.41^{* * *}\end{array}$ & $\begin{array}{c}0.08^{* *} \\
(2.10) \\
0.60^{* * *} \\
(16.30)\end{array}$ \\
\hline Path & & & $(13.75)$ & 144 \\
$R^{2}$ & 144 & 144 & 144 & 0.66 \\
\hline
\end{tabular}

Notes: This table reports the response of interest rates to the target and path factor as described in the text. The sample consists of all monetary policy announcements in the period January 1994-December 2009. For each Treasury yield, we estimated $\Delta y_{t}=\alpha+\beta Z_{t}+\epsilon_{t}$, with $y_{t}$ a one-year or ten-year Treasury note and $Z_{t}$ the target factor or a vector containing target and path factor. Student t-statistics are in parentheses. $*, * *$, and $* * *$ denote $\mathrm{p}<0.1, \mathrm{p}<0.05$, and $\mathrm{p}<0.01$, respectively.

by Gürkaynak, Sack, and Swanson (2005), who write: "FOMC statements that move one-year-ahead policy expectations appear to have much greater effects on the long end of the yield curve than do changes in the federal funds rate."

Further analysis of the path variable can be found in the article by Gürkaynak, Sack, and Swanson (2005), where the authors (i) contrast the pre-1994 and post-1994 period, (ii) present a regression test of path factor by considering the effect of the presence of a statement on the path factor, and (iii) discuss the largest values of the path factor. Since February 1994, the FOMC has issued a press release after every meeting and policy change. As a result, a simple test for the path factor exploiting the presence of a statement is no longer feasible and we refer the reader to Gürkaynak, Sack, and Swanson (2005) for the convincing results of such a test with pre-2004 data. All the important dates in their paper (sample ends in 2004) are influential dates according to our path factor as well, although we see quite a few additionally in 2007-09.

We end this section by providing summary statistics of both factors. Table 3 presents some descriptive statistics during expansions and during recessions. These descriptives emphasize the fact that both the target factor and the path factor become more variable in downturns. 
Vol. 13 No. 1

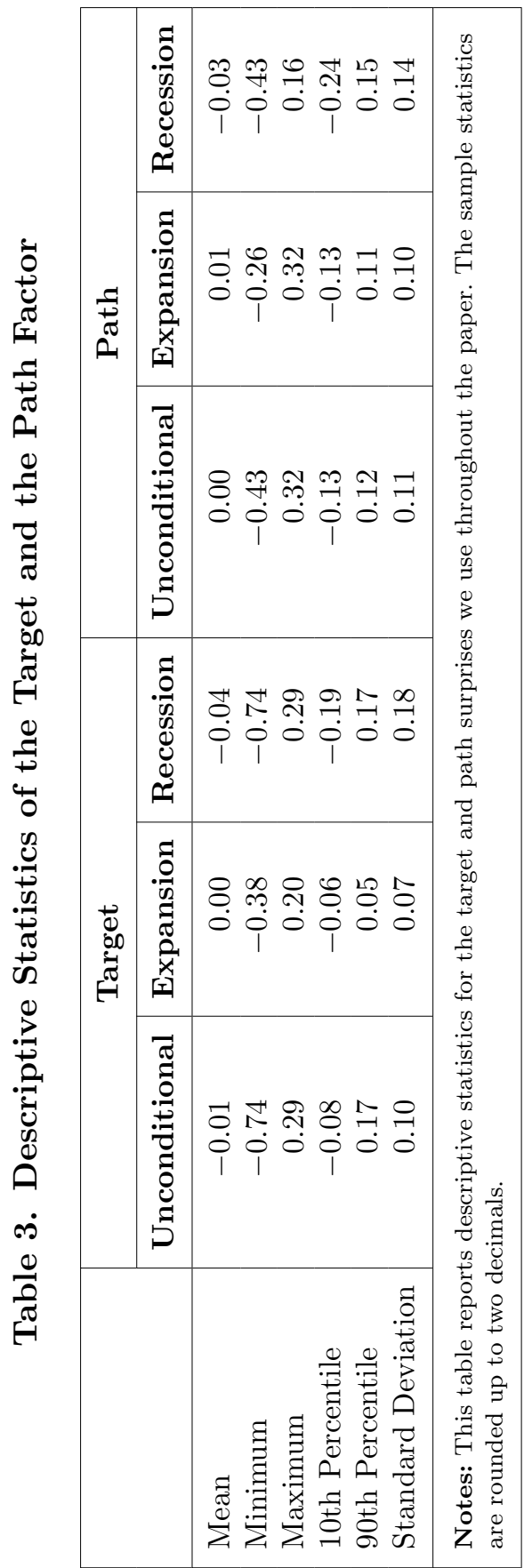




\section{Event-Study Analysis}

In this section, we undertake our benchmark event study. In the subsequent sections we extend this benchmark study to explore cross-sectional variation. The basic linear model we estimate is the following:

$$
\begin{aligned}
\operatorname{Return}_{i t}= & \alpha+\gamma \operatorname{Rec}_{t}+\beta_{1} \operatorname{Target}_{t}+\beta_{2} \operatorname{Target}_{t} * \operatorname{Rec}_{t}+\beta_{3} \operatorname{Path}_{t} \\
& +\beta_{4} \operatorname{Path}_{t} * \operatorname{Rec}_{t}+\epsilon_{i t},
\end{aligned}
$$

where the variables Target $t$ and $\mathrm{Path}_{t}$ are the variables discussed in subsection 2.2. The regressand Return ${ }_{i t}$ is the return on stock $i$ at time $t$, and $\operatorname{Rec}_{t}$ is a dummy variable to account for the business cycle. Rec $c_{t}$ takes the value of 1 in a recession and the value of 0 otherwise. We use the NBER recession indicators as our primary recession indicator. As a robustness check, we also consider alternative recession indicators (see further). In the context of monetary policy actions, several studies have found that the reaction of stocks is more pronounced during recessions; see, for example, Basistha and Kurov (2008) or Kurov (2010). We estimate six variants of this model and present the results in table 4. All specifications presented here, and in the remainder of the paper, are estimated with firm fixed effects (least-squares dummy variable, or LSDV) and heteroskedasticity-consistent standard errors unless mentioned otherwise. The specification with firm fixed effects and robust standard errors is our preference in this application. The fixed effects account for unobserved heterogeneity due to time-constant firm characteristics, while the robust standard errors capture non-constant variance of the errors without imposing a specific clustering structure. Some readers may feel that a specific clustering structure is warranted and that we should use standard errors constructed to accommodate this. In section 7 and the online appendix, we discuss the robustness checks we carried out (a variety of alternative error-construction procedures) which confirm that the results we present in this paper are robust.

The first step in our analysis is to estimate the model as it is presented above, that is, with individual stock returns over the whole sample. Second, we estimate the same model but we now use aggregate returns on the S\&P 500 index as a dependent variable. This 


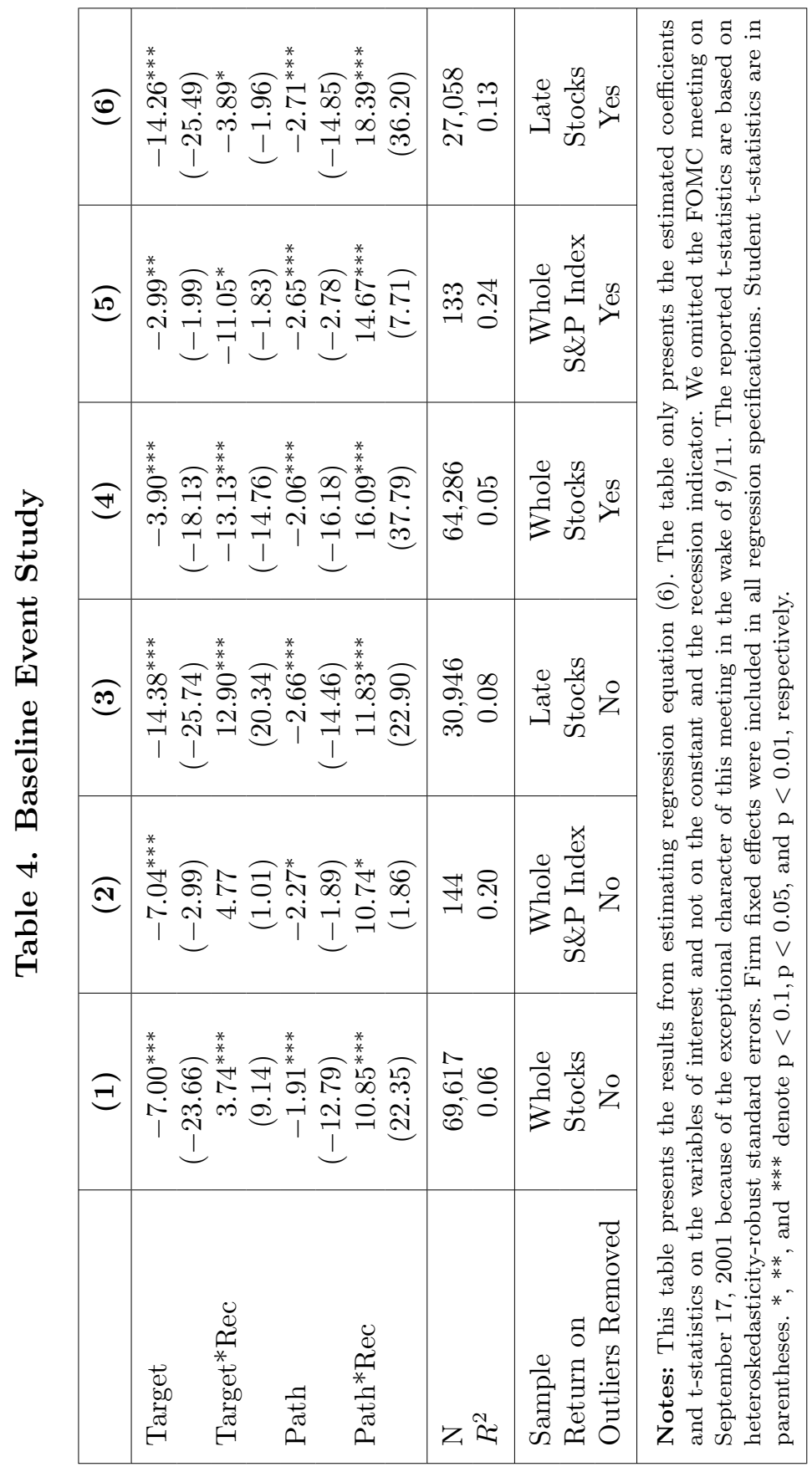


serves as a robustness check for the model with individual returns on which we build in subsequent sections. Third, we estimate the model again with individual returns as the dependent variable, but now the sample is restricted to the period after the introduction of forwardlooking statements in FOMC communications. Fourth, we estimate the model with individual returns as a dependent variable and over the whole sample, but now we drop outlier dates. As pointed out by Bernanke and Kuttner (2005), there is the concern that exceptional FOMC meetings may generate the results we present in the paper. In particular, our recession indicator captures the onset of the financial crisis in 2008-09. By removing outlier dates, we aim to show that our results are not driven by a few exceptional trading days. We identify outliers by estimating regression (6) with returns on the S\&P 500 index as a dependent variable. Then we use the DFITS statistic of Welsh and Kuh (1977) to find influential dates. Using the cut-off value proposed by Belsley, Kuh, and Welsh (1980), we determine the dates that are marked as outliers. A brief overview of the dates marked as outliers as well as alternative procedures to determine outliers can be found in the online appendix to this paper. In that appendix we also discuss the robustness of our results with respect to the outlier choice. In the fifth and the sixth specification, we reestimate the second and the third specification while omitting outlier dates.

Inspection of the estimation results in table 4 reveals that the estimated coefficients are quite similar over all specifications presented. We point to some results which are important for our further discussion. First, we find a negative coefficient on the target factor, a result in line with theory and earlier empirical work; see, for example, Ehrmann and Fratzscher (2004). Second, the coefficient on the path factor is also negative but smaller in absolute value. The negative sign suggests that in good times (i.e., the recession dummy equals zero) an upward revision of the future path of monetary policy depresses stocks. Third, we notice that state dependence matters. Interacting both factors with a recession indicator improves the fit of the model greatly and allows for much more precise estimates of the target and the path factor. When we regressed the S\&P 500 index return on the target and the path factor without interaction terms and over the entire sample, we found very large standard errors and an $R^{2}$ statistic less than 0.06 (compared with 0.2 or more 
when interactions were included) 18 The sign on the target-recession interaction term is ambiguous and depends on whether outlier dates are included. If we consider the whole sample, the sign is positive; if we drop the outlier dates, then the sign becomes negative. However, our main interest is in the path-recession interaction, which is found to be positive across all specifications presented. The pathrecession interaction coefficients imply that communication inducing an upward revision of the expected path of future policy during a recession has a positive effect for the average stock return. With the descriptive statistics from table 3 in mind, we can get a feel for the economic significance of the results. For example, one in five FOMC meetings in a recession is associated with a path surprise of more than 15 basis points in absolute value. The regression results in column 4 indicate that a path surprise of 15 basis points has an impact of more than 2 percent on the average stock return, with the sign depending on whether it was a positive or negative path surprise. The overall impact of a particular meeting also depends on the target factor. However, with the exception of a few remarkable meetings in which the FOMC surprised the financial markets, the target factor has become less important. The calculation we did was based on regression results on a sample in which we excluded the most influential policy dates, and thus lends support to our main hypothesis. Central bank communication, captured here by the path factor, has a non-negligible influence on financial markets. Moreover, its effect in downturns is opposite to the effect in expansions. One explanation could be that financial market participants read FOMC communications to update their views on the state of the economy. A future tightening of the policy rate during a downturn suggests that the Federal Reserve, with its dual mandate and reluctance to raise the federal funds rate too soon, hints at better economic times ahead. Pinning this down is an arduous task, but at least there is an extensive literature arguing that the Federal Reserve outperforms private forecasters. The seminal article in this literature is Romer and Romer (2000), but other articles using various techniques and sample choices support the idea of superior forecasting performance. See, for example, Sims (2002), Peek, Rosengren, and Tootell

\footnotetext{
${ }^{18}$ This corresponds to the regression we estimated in columns 2 and 4 of table 4 but with coefficients $\gamma, \beta_{2}$, and $\beta_{4}$ restricted to be zero.
} 
(2003), and D'Agostino and Whelan (2008). El-Shagi, Giesen, and Jung (2014) extend the work by Romer and Romer (2000) and show that the forecast performance of the Federal Reserve is relatively better when there is increased uncertainty. Moreover, better knowledge of the FOMC staff on the Federal Reserve's future interest rate path plays an important role in the superior forecasting performance. This suggests that private forecasters can learn from central bank forecasts of key economic variables and adapt their views on the economy accordingly; see El-Shagi, Giesen, and Jung (2014).

When comparing the results of regressions over the whole sample with regressions over the sample starting after the introduction of forward-looking statements (columns 3 and 6 in table 4), we notice that the results are in line with each other. The most noticeable difference is that the model fit improves when we restrict ourselves to the later sample. The sign of the variables in the regressions remains the same. For this reason we prefer to use the whole sample 19

We are hesitant to take a strong stance on whether we should base the analysis on the sample with or without outliers. Both choices have their merits. By excluding outliers, we show that the results do not depend crucially on a few FOMC meetings. On the other hand, the outlier dates are likely to reflect important policy dates. Excluding them may give an imperfect picture of exceptional times. In the remainder of this study, we present results excluding outliers.

An important motivation for considering individual stock returns is that we expect a large heterogeneity in responses among stocks. In the following sections, we investigate the responses of stocks in more detail by considering firm- and industry-specific effects.

\section{Industry Effects}

In this section, we relate the responses of stock prices to industry affiliation. Industry-specific effects may arise through the

\footnotetext{
${ }^{19}$ In an earlier version of this paper, we emphasized the regime change due to the introduction of forward-looking statements. While the size of the estimated coefficients and the precision changes, the conclusions presented in this paper carry over to the case where we use a smaller sample. In the online appendix to this paper, we present some regression results with the late subsample as a robustness check.
} 
interest channel. Industries with a more interest-sensitive demand are expected to be more responsive to Federal Reserve communication. The cross-sectional dimension of monetary policy has been studied by a few papers. Peersman and Smets (2005) study the effects of monetary policy on sectoral production indices across OECD and euro-area countries. Hayo and Uhlenbrock (2000) study industry effects within Germany. Ehrmann and Fratzscher (2004) and Bernanke and Kuttner (2005) explore the cross-sectional effects of monetary policy actions on stock returns in the United States. Our analysis differs from these studies in the following ways. First, we allow for dependence on the business cycle. Monetary policy may have different effects depending on the business cycle which we capture by including interaction terms. Secondly, we adhere to the twofactor view introduced earlier and we distinguish between a current federal funds rate target factor and a future path of policy factor. Third, we tie the industry effects we observe to the cyclicality of industries.

In their paper considering the effect of the target factor on stock prices, Ehrmann and Fratzscher (2004) suggest that industry differences in responsiveness are likely due to differences in cyclicality. They do not test for this and only provide a heuristic argument. We expect a similar mechanism to work here as well. When state dependence matters, we expect industries, which are more susceptible to the business cycle (cyclical industries), to show more pronounced responses.

In order to pin this down, we need to determine which industries can be classified as cyclical. A way to classify industries in terms of cyclicality was put forward in Boudoukh, Richardson, and Whitelaw (1994) and we follow that approach, in which industries are ranked according to the industrial production growth beta. More specifically, we construct sectoral growth rates of industrial production and the growth rate of the aggregate industrial production. The industrial production growth beta is then the estimated coefficient of a regression of the sectoral growth rate on the aggregate growth rate:

$$
\mathrm{IPG}_{t}=\alpha+\beta \text { Aggregate } \mathrm{IPG}_{t}+\epsilon_{t},
$$

where IPG stands for industrial production growth rate. This model is estimated for each industrial sector covered by the G17 Federal 
Reserve data. The data is sampled quarterly from 1972 until 2009. The results are reported in table 5 . The column in the middle of table 5 reveals substantial variation in growth betas across industries ranging from coefficients below 0.3 for food, beverages, tobacco, and electric power generation to coefficients larger than 2 for primary metal and motor vehicles. The column on the right presents the standardized betas which we use in our analysis.

To see whether more cyclical industries are more responsive to monetary policy, we estimate the following regression:

$$
\begin{aligned}
\operatorname{Return}_{i k t}= & \alpha+\gamma \operatorname{Rec}_{t}+\beta_{1} \text { Target }_{t}+\beta_{2} \text { Path }_{t}+\beta_{3} \text { Target }_{t} * \operatorname{Rec}_{t} \\
& +\beta_{4} \text { Path }_{t} * \operatorname{Rec}_{t}+\beta_{5} \operatorname{Target}_{t} * \text { Cyclical }_{k} \\
& +\beta_{6} \text { Path }_{t} * \text { Cyclical }_{k}+\beta_{7} \text { Target }_{t} * \operatorname{Rec}_{t} * \text { Cyclical }_{k} \\
& +\beta_{8} \text { Path }_{t} * \operatorname{Rec}_{t} * \text { Cyclical }_{k}+\epsilon_{i k t}
\end{aligned}
$$

where the subscripts $i, k, t$ indicate firm $i$ in industry $k$ at time $t$ and Cyclical is a cyclicality indicator. In table 6 , we present the results of this regression with two different cyclicality indicators. In the column on the left, we present the regression result where the standardized production growth betas are used as cyclicality indicators. In the column on the right, we present the results when using a ternary indicator, taking the value of -0.5 when the stock belongs to the industries which are the least cyclical, 0.5 when the stock belongs to the most cyclical industries, and 0 when it falls between these extremes. The most (least) cyclical are the industries containing the upper (lower) quintile of observations when we rank the industrial sectors according to the industrial production growth betas as we did in table 5. This corresponds to the top eight and bottom three industrial sectors, respectively. Coding the upper and lower group as +0.5 and -0.5 makes the interpretation of the estimated regression coefficients straightforward; a one-unit increase in the explanatory variable now corresponds to a shift from the lower to the upper quintile, as the regression coefficient is now just the difference between the upper and the lower quintile 20

We estimate equation (8) for all firms in industries which are covered by the Federal Reserve statistical release data on industrial

\footnotetext{
${ }^{20}$ This approach is discussed in section 2.8 of Gelman and Park (2009).
} 


\section{Table 5. Cyclicality of Industrial Sectors}

\begin{tabular}{|c|c|c|}
\hline Industrial Sector (Sorted on $\beta$ ) & $\boldsymbol{\beta}$ & Standardized $\beta$ \\
\hline Motor Vehicles and Parts & $2.819^{* * *}$ & 2.679 \\
\hline Primary Metal & $2.378^{* * *}$ & 1.995 \\
\hline Plastics and Rubber Products & $1.565^{* * *}$ & 0.732 \\
\hline Electronic Equipment & $1.483^{* * *}$ & 0.605 \\
\hline Furniture & $1.483^{* * *}$ & 0.605 \\
\hline Machinery & $1.377^{* * *}$ & 0.440 \\
\hline Wood Production & $1.305^{* * *}$ & 0.328 \\
\hline Fabricated Metal Products & $1.288^{* * *}$ & 0.302 \\
\hline Computer and Electronic Products & $1.265^{* * *}$ & 0.266 \\
\hline Non-metallic Mineral Products & $1.234^{* * *}$ & 0.218 \\
\hline Textile Production & $1.211^{* * *}$ & 0.182 \\
\hline Chemical & $1.004^{* * *}$ & -0.139 \\
\hline Paper & $0.980^{* * *}$ & -0.176 \\
\hline Apparel and Leather Goods & $0.862^{* * *}$ & -0.360 \\
\hline Miscellaneous & $0.738^{* * *}$ & -0.552 \\
\hline Printing & $0.611^{* * *}$ & -0.750 \\
\hline Petroleum and Coal Products & $0.600^{* * *}$ & -0.767 \\
\hline Mining & $0.494^{* * *}$ & -0.931 \\
\hline $\begin{array}{l}\text { Aerospace and Miscellaneous } \\
\text { Transportation }\end{array}$ & $0.428^{* *}$ & -1.034 \\
\hline Natural Gas Distribution & $0.407^{* * *}$ & -1.066 \\
\hline Electric Power Generation & $0.292^{* * *}$ & -1.245 \\
\hline Food, Beverage, Tobacco & $0.236^{* * *}$ & -1.332 \\
\hline \multicolumn{3}{|c|}{$\begin{array}{l}\text { Notes: The second column presents the industrial production growth betas. These } \\
\text { betas are estimated using the following model for each separate sector: } \mathrm{IPG}_{t}=\alpha+\beta \\
\text { Aggregate } \mathrm{IPG}_{t}+\epsilon_{t} \text {, where IPG stands for industrial production growth. We estimate } \\
\text { this for each sector for which have data available (see the online data appendix). The } \\
\text { reported p-values are based on Newey-West standard errors. In the third column, we } \\
\text { present the standardized betas. We calculate these by taking the estimated betas, } \\
\text { subtracting the mean }(1.093636) \text { and dividing by the standard deviation }(0.643924) \\
\text { and rounding up to three decimals. }{ }^{*},{ }^{* *} \text {, and }{ }^{* * *} \text { denote } \mathrm{p}<0.1, \mathrm{p}<0.05 \text {, and } \\
\mathrm{p}<0.01 \text {, respectively. }\end{array}$} \\
\hline
\end{tabular}

production (all industries covered in table 5). The results can be found in table 6 .

Inspection of table 6 confirms that industry patterns in the response of stock returns to monetary policy can partially be traced 
Table 6. Responses of Cyclical and Non-cyclical Industries

\begin{tabular}{|c|c|c|}
\hline & Standardized $\boldsymbol{\beta}$ & Low vs. High \\
\hline Target & $\begin{array}{l}-2.86^{* * *} \\
(-5.98)\end{array}$ & $\begin{array}{l}-3.63^{* * *} \\
(-12.31)\end{array}$ \\
\hline Target*Rec & $\begin{array}{l}-5.92^{* * *} \\
(-3.03)\end{array}$ & $\begin{array}{l}-12.18^{* * *} \\
(-10.72)\end{array}$ \\
\hline Path & $\begin{array}{l}-0.25 \\
(-0.83)\end{array}$ & $\begin{array}{l}-1.72^{* * *} \\
(-10.59)\end{array}$ \\
\hline Path*Rec & $\begin{array}{l}3.59^{* * *} \\
(4.18)\end{array}$ & $\begin{array}{l}12.24^{* * *} \\
(25.11)\end{array}$ \\
\hline Target ${ }^{*} \mathrm{Cycl}$ & $\begin{array}{l}-0.82^{*} \\
(-1.87)\end{array}$ & $\begin{array}{l}-2.10^{* *} \\
(-2.50)\end{array}$ \\
\hline Target*Rec*Cycl & $\begin{array}{l}-6.47^{* * *} \\
(-3.53)\end{array}$ & $\begin{array}{l}-11.92^{* * *} \\
(-3.63)\end{array}$ \\
\hline Path*Cycl & $\begin{array}{l}-1.53^{* * *} \\
(-5.78)\end{array}$ & $\begin{array}{l}-2.74^{* * *} \\
(-6.46)\end{array}$ \\
\hline Path*Rec*Cycl & $\begin{array}{l}9.08^{* * *} \\
(10.22)\end{array}$ & $\begin{array}{l}13.21^{* * *} \\
(9.87)\end{array}$ \\
\hline \multicolumn{3}{|c|}{$\begin{array}{l}\text { Notes: This table presents the results from estimating equation ( } 8 \text { ). The column } \\
\text { on the left presents the results when using the standardized betas (see table } 5 \text { ) as } \\
\text { a cyclicality indicator. The column on the right uses a ternary indicator coded such } \\
\text { that the coefficient on the cyclicality interaction represents the difference between } \\
\text { high cyclical and low cyclical firms. The table presents the estimated coefficients } \\
\text { and t-statistics on the variable of interest only, and not on the constant. The report } \\
\text { t-statistics are based on heteroskedasticity-robust standard errors. We omitted the } \\
\text { FOMC meeting on September } 17,2001 \text { because of the exceptional character of this } \\
\text { meeting in the wake of } 9 / 11 \text {. We also omitted eleven dates marked as outliers, as } \\
\text { explained in the text. Firm fixed effects were included in all regression specifications. } \\
\text { Student t-statistics are in parentheses. } * * * \text {, and } * * * \text { denote p }<0.1, p<0.05 \text {, and } \\
\text { p }<0.01 \text {, respectively. }\end{array}$} \\
\hline
\end{tabular}

back to the cyclicality of the industry. Both specifications indicate that the impact of monetary policy is more pronounced for companies operating in cyclical industries. In the column on the left, we use the standardized production growth betas as an interaction term. We see that for a company operating in the textile production industry, a manufacturing industry with a typical co-movement with the business cycle, a positive path surprise of 15 basis points has a negligible impact on the stock return. Contrast this with the impact 
on the stock of a company operating in a highly cyclical industry. For example, using the results in tables 5 and 6 , we expect for a company operating in the primary-metal-producing industry the impact of a path surprise 15 basis points to be $-1.53 \times 15 \times 1.995 \approx-45$ basis points, whereas a similar calculation yields approximately -4 basis points for the textile industry. When we consider the impact on stock returns in a downturn, we get a larger and positive impact, as we emphasized throughout this paper. For the textile industry, the impact on the average stock return is estimated to be nearly +0.35 percent, while the impact on stocks from firms operating in a highly cyclical industry like primary metal is estimated to be about +2.8 percent 21

In the right column, the coefficient on the interaction with the cyclicality indicator represents a shift from the lower quintile to the upper quintile, as explained above. The results show that we expect the impact of central bank communication (i.e., the path factor) in a downturn to be more than twice as large when comparing stocks in the bottom and upper cyclical industries.

The results shown in table 6 confirm our priors. The effects of central bank communication are in line with central bank actions. For central bank actions - i.e., surprise changes in the policy rateEhrmann and Fratzscher (2004) showed in a series of industry-byindustry regressions that industries which are more cyclical show a more pronounced response. As an example, they found that stocks belonging to the electrical equipment major group are twice as sensitive as stocks in the chemicals group. Our results can be seen as an extension. We show that the same pattern carries through for the two factors and the recession interactions. Furthermore, we aimed at explaining cross-sectional variation with a variable capturing cyclicality. Our results confirm the idea that cyclical industries tend to be more responsive to central bank actions and communication.

We now turn to firm-specific effects.

\footnotetext{
${ }^{21}$ In a recession we add $3.59 \times 15+9.08 \times 15 \times 0.182 \approx 80$ for the textile industry and $3.59 \times 15+9.08 \times 15 \times 1.995 \approx 325$ for the primary-metal-producing industry, yielding an impact of nearly +35 and about +280 basis points for these industries, respectively.
} 


\section{Firm-Specific Effects}

There is a substantive literature on the credit channel of monetary policy transmission documenting asymmetric effects of monetary policy on firms. This literature emphasizes that firms facing financial constraints are more affected by changes in interest rates than firms that are less constrained. The literature on the credit channel of monetary policy transmission broadly suggests two reasons why some firms are affected more than others. Worsening credit markets affect the balance sheets of firms and thus affect the present value of collateral; see Bernanke and Gertler (1989). This is sometimes referred to as the balance sheet channel. In worsening credit market conditions, the firms for which there is the least information are also the first to get cut from credit lines. This is referred to as the bank lending channel.

The literature has spurred a variety of proxies for financial constraints. A popular proxy for credit constraints is firm size. Studies by Gertler and Gilchrist (1994), Perez-Quiros and Timmermann (2000), and Ehrmann and Fratzscher (2004) find that smaller firms are more affected by monetary policy tightening than larger firms. Other proxies for financial constraints rely on financial ratios. A variety of capital and book ratios were tested in a study by Kaplan and Zingales (1997).

In this paper we investigate cross-sectional variation at the firm level and consider six proxies for financial constraints. Our notion of financial constraints follows Kaplan and Zingales (1997) and Ehrmann and Fratzscher (2004). Firms facing more financial constraints find it relatively more difficult to raise funds. The first two variables we consider are the total amount of assets of a firm and the number of employees. Both quantities capture the size of the firm. Next, following papers by Kaplan and Zingales (1997), Lamont, Polk, and Saa-Requejo (2001), and Ehrmann and Fratzscher (2004), we consider the cash-flow-to-income ratio and the debt-to-assets ratio. The idea is that firms with relatively large cash flows or low debt face fewer financial constraints, as they have lower external financing needs. Finally we consider the return on equity (a measure of profitability) and trade credit. Trade credit is considered to be a particularly expensive form of finance and was also used in Basistha and Kurov (2008) to capture financial constraints. As 
argued in Nilsen (2002), financially constrained firms are more likely to resort to trade credit than less constrained firms.

To investigate the cross-sectional variation across firms, we estimate the following regression:

$$
\begin{aligned}
\text { Return }_{i t}= & \alpha+\gamma \operatorname{Rec}_{t}+\beta_{1} \operatorname{Target}_{t}+\beta_{2} \operatorname{Path}_{t}+\beta_{3} \operatorname{Target}_{t} * \operatorname{Rec}_{t} \\
& +\beta_{4} \operatorname{Path}_{t} * \operatorname{Rec}_{t}+\beta_{5} \operatorname{Target}_{t} * \operatorname{Firm}_{i t}+\beta_{6} \operatorname{Path}_{t} * \operatorname{Firm}_{i t} \\
& +\beta_{7} \operatorname{Target}_{t} * \operatorname{Rec}_{t} * \operatorname{Firm}_{i t}+\beta_{8} \operatorname{Path}_{t} * \operatorname{Rec}_{t} * \operatorname{Firm}_{i t} \\
& +\sum_{j=1}^{3} \delta_{j} \operatorname{Control}_{j, i t}+\epsilon_{i t}
\end{aligned}
$$

where Firm is a firm-specific variable capturing the financial constraint a firm faces. The Control ${ }_{j}$ 's are three firm-level control variables. Following Laeven and Tong (2012), we include the three Fama and French (1992) factors as firm characteristics directly in our regression as control variables 22

We estimate this model with the six different Firm variables explained above: the number of employees, the total amount of assets, cash flow to net income, return on assets, trade credit, and debt to assets. We rank the firms for each FOMC meeting according to their position in the cross-sectional distribution of the variable under consideration. We then divide the firms into three groups: the lower quintile, the upper quintile, and the middle group. This categorization on a daily basis allows for temporal changes in the financial constraints firms face. We then code the variable Firm as taking the value of -0.5 for the quintile we expect to be the least financially constrained, 0 for the middle group, and +0.5 for the quintile we expect to be the most constrained. For the variables we consider, we expect the least financially constrained firms to be those firms with the most employees, the largest amount of assets, the largest cash flow to income, the least trade credit, and the lowest

\footnotetext{
${ }^{22}$ Details on the construction of these control variables (Market to Book, Size, and Beta) can be found in the online appendix. Laeven and Tong (2012) motivate the inclusion by referring to the asset pricing literature. Direct inclusion of the firm characteristics rather than estimating a factor model is easier to implement and should not matter in this context substantially; see Laeven and Tong (2012).
} 
debt-to-assets ratio. The variable Firm is then interacted with the variables of interest to gauge the impact of moving from the least financially constrained group to the most financially constrained group.

Following Laeven and Tong (2012), we drop firms active in the utilities industry, the wholesale industry, the financial industry, and public administration. These firms are subject to strict regulation or they have strongly differing financing needs, and keeping these in our sample would confound the results. In table 7 , we provide correlations between the Firm variables we consider. The table illustrates that the different Firm variables we consider have very low correlations except for the two variables capturing firm size: the number of employees and the total amount of assets.

The results of estimating regression model (9) are provided in table 8. In the first two columns, Firm is an indicator variable capturing the size of the firms in terms of employees and total assets, respectively. Firms are ranked such that the large firms are in the bottom quintile and the small firms are in the top quintile. The results for both specifications are similar and show that smaller firms tend to be more responsive to central bank communication in downturns. When considering a path surprise in a downturn of 15 basis points, we expect an additional impact of over 85 (40) basis points on the stock return when comparing the 20 percent smallest companies with the 20 percent largest companies as measured by the number of employees (total assets). When proxying financial constraints by a low cash-flow-to-income ratio, a low return on equity, or a high trade credit, we find similar results. What is noticeable is that we only find weak evidence of firm effects in the target factor. In only one of the first five specifications, we find that the target factor is significantly negative for firms facing financial constraints. We notice that in general all the estimated coefficients on the firm interactions have the sign we would expect. However, only the coefficient on the path-recession-firm interaction is statistically distinguishable from zero in all of the first five specifications. In the last specification we present, we do not find a difference between firms carrying a low and high amount of debt. This does not contradict previous findings, as Ehrmann and Fratzscher (2004) found that the effect of debt is non-linear: "Firms with either high or low values of these ratios 


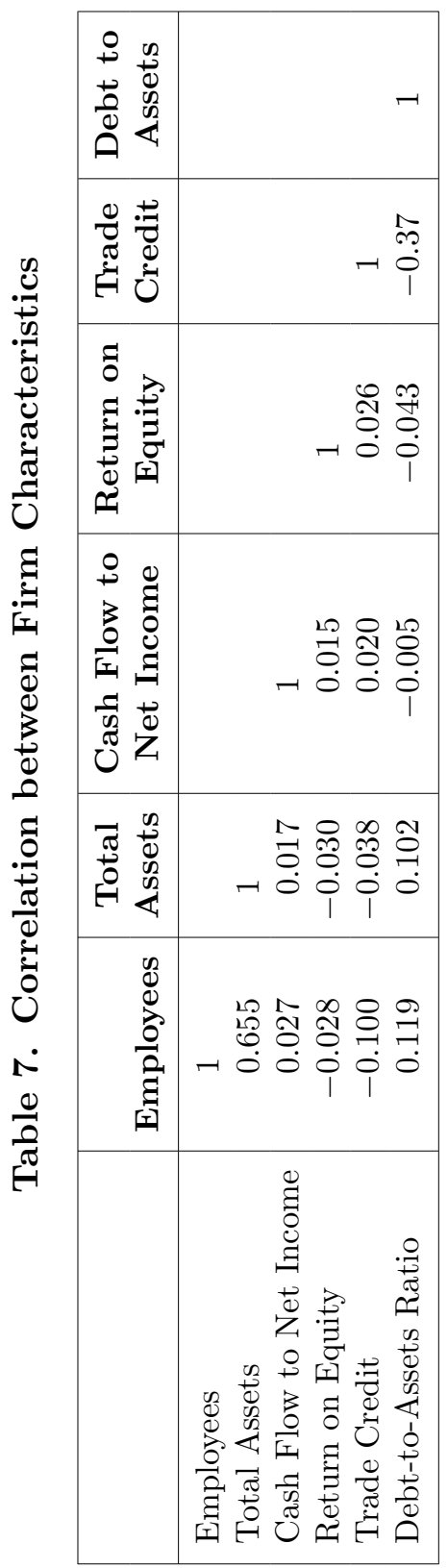




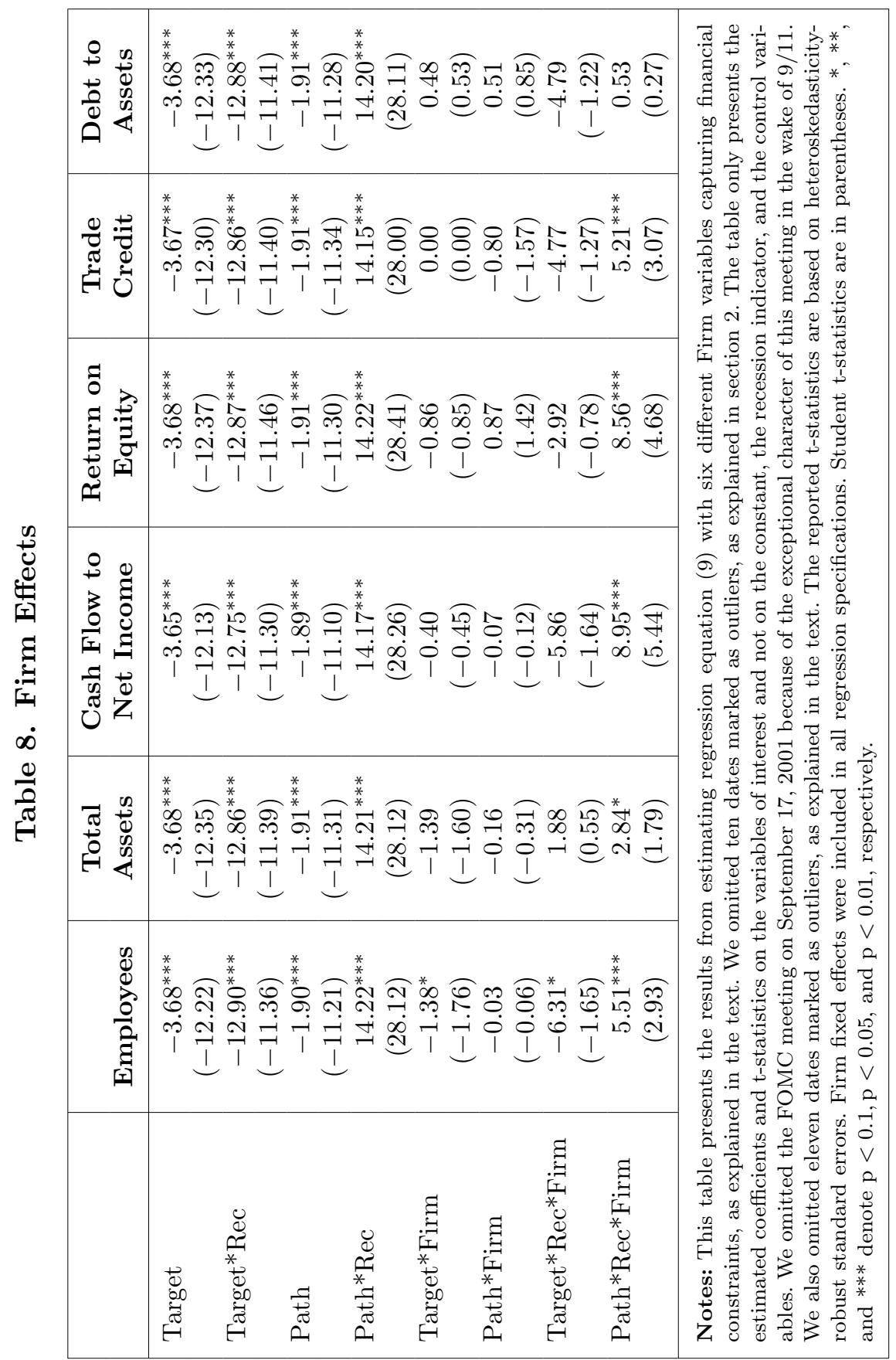


[debt-to-capital ratio] respond more than firms with intermediate levels"; see Ehrmann and Fratzscher (2004, p. 731). Our specification is restrictive, as it only allows for a monotonous effect. When we estimate a specification that allows for this non-linearity, we find that this also applies here for path-recession interaction. We report these results in the online appendix to this paper. As a robustness check, we also estimated this specification for the other proxies for financial constraints. The results are in line with what we presented above and do not reveal similar non-linearities as in the case of the debt-to-assets ratio.

Taken together, the results in table 8 show that the asymmetric response of stocks to the path factor in a downturn can be explained by the degree to which they are financially constrained 23

\section{The Pre-FOMC Announcement Drift}

Recent work by Lucca and Moench (2015) documents large excess returns in anticipation of scheduled FOMC meetings. This announcement drift, as the authors remark, is uncorrelated with the unexpected component of the yet-to-be-realized policy decision or the conditional response to the actual announcement. Lucca and Moench (2015) stress the difference between their findings and those of the event-study literature into which our paper falls. That is, their findings relate to unconditional excess returns ahead of policy meetings. However, with the knowledge that the U.S. equities show peculiar behavior in anticipation of the FOMC meetings, it is useful to test what happens to our results when we cut out the anticipation effect. To do this, we reestimate our baseline regressions (given by equation (6)) but we now use two different stock market returns. First, we construct a return from 2:00 p.m. the previous trading day until 2:00 p.m. of the FOMC meeting day, and, second, we construct a return from 2:00 p.m. on the FOMC meeting day until 2:00

\footnotetext{
${ }^{23} \mathrm{~A}$ referee asked whether the effect of financial constraints is different from the cyclicality effect, i.e., the stronger response of smaller firms might not be due to financial constraints but rather to the fact that they are more cyclical. In the online appendix to this paper, we report regression results showing that these are two different effects.
} 
p.m. the next trading day. The former return we call ReturnMin and the latter return we call ReturnPlus. ReturnMin captures the anticipation of the FOMC meeting but not the FOMC meeting itself. ReturnPlus, on the other hand, captures the surprises while avoiding the anticipation as in Lucca and Moench (2015) 24 The results are presented in table 9 . The first and the fourth column present results corresponding to our baseline results, i.e., with returns calculated as throughout the paper. The results serve as the benchmark against which to compare the other results. Our sample is a little shorter due to data limitations, as we have only access to TAQ data from 2001 onwards. The first column shows the results when keeping all FOMC meeting days, whereas in column 4 we have removed outlier observations, as we did throughout the paper. The results in these columns are in line with what we have shown earlier, although the estimate on the path-recession interaction in column 1 is very noisy and we do not have a significant coefficient (t-statistic of about 1.5). The point estimate is, however, positive and large, and when outliers are removed, we have a significant positive coefficient on this interaction. Consider now the results for ReturnMin. We see that the $R^{2}$ is substantially lower and our findings disappear. This suggests that it is not the anticipation period which leads to our main results. On the other hand, when we consider the results for ReturnPlus, the $R^{2}$ increases and we again see a positive coefficient for the pathrecession interaction. For our sample with all meetings included, the coefficient is lower and not significant. Taken together, we feel that these results show that the preannouncement drift does not play a major role in our event study. We notice that in the first column the results are a little weaker than the results of our baseline event study, but our sample has fewer observations, reducing the power of the statistical tests.

\footnotetext{
${ }^{24}$ This design mimics the setup in Lucca and Moench (2015). We use highfrequency data from the TAQ database on SPY to create these returns. We average all prices in the TAQ database between 13:59:00 and 14:00:00, after which we calculate returns. We only have access to TAQ data for the period March 2001 up to and including September 2009.
} 


\begin{tabular}{|c|c|c|c|c|}
\hline 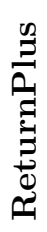 & 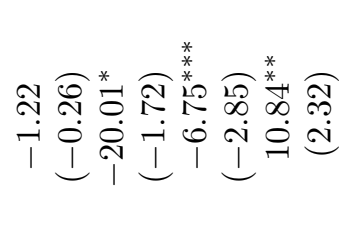 & $\mathbb{N} \stackrel{\vec{N}}{0}$ & $\underset{\nu}{\theta}$ & 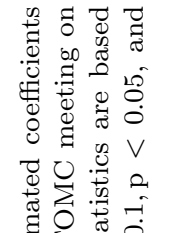 \\
\hline$\sum_{\substack{\Xi \\
\Xi}}^{\Xi}$ & 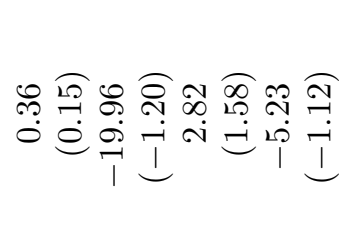 & $\stackrel{+}{\rightleftarrows}$ & $\underset{\gamma}{\theta}$ & 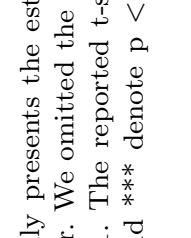 \\
\hline 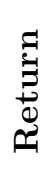 & 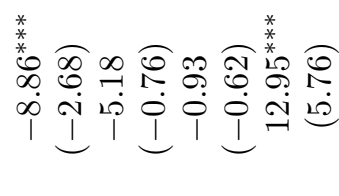 & स & $\stackrel{0}{\theta}$ & 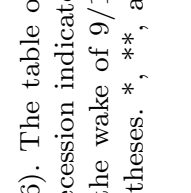 \\
\hline 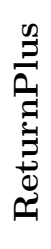 & 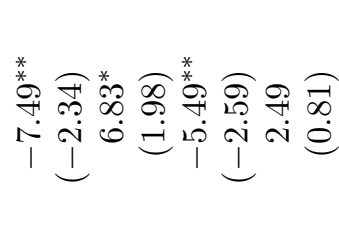 & $\underset{\infty}{+} \stackrel{0}{\stackrel{0}{0}}$ & 兄 & 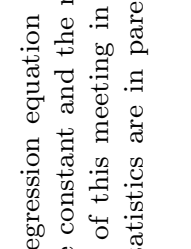 \\
\hline 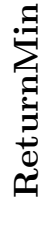 & 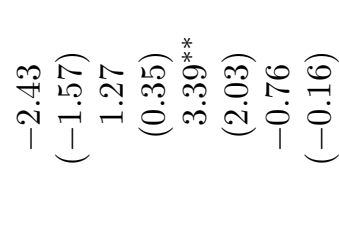 & + $\stackrel{\infty}{\infty}$ & 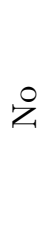 & 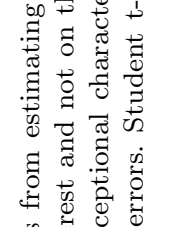 \\
\hline 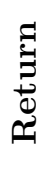 & 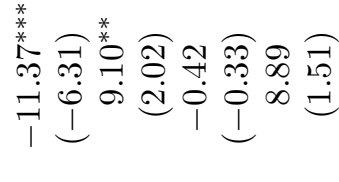 & $\uplus_{\infty}^{+} \stackrel{\dddot{0}}{0}$ & $\stackrel{0}{z}$ & 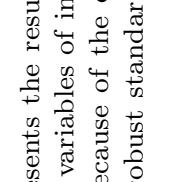 \\
\hline & 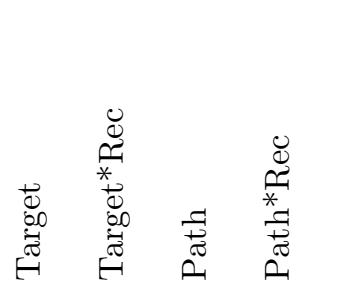 & 乙会 & 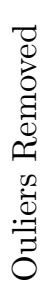 & 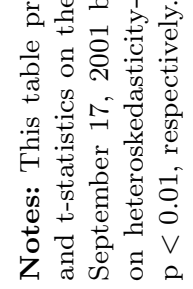 \\
\hline
\end{tabular}




\section{Further Robustness Checks}

We have performed additional checks to ensure that the findings are robust. Tables with results from some of these checks can be found in the online appendix to this paper.

\subsection{Alternative Approaches to Outlier Detection}

In the online appendix to this paper, we consider alternative ways to detect outliers. These include the use of a different outlier statistic, relying on a subsample instead of the entire sample to detect outliers or using a baseline regression without a recession dummy to pick up outliers. All procedures pick up by and large the same outlier dates. Since the regression results without outliers are in line with the regression results with outliers, we are convinced of the robustness of our results. As mentioned earlier, we chose to base our analysis on a sample from which we have omitted outliers. The reason is that some meetings are exceptional, and commenters have expressed a concern that these special meetings might confound our results. Building our event study on a sample without outlier dates and checking our regression results on subsamples (as mentioned above) alleviates these concerns.

\subsection{Standard Errors}

The appropriate choice of standard errors in studies with finance panel data sets is rarely clear-cut. Petersen (2009) provides a detailed study on the different ways of calculating standard errors in the finance literature. In this paper, we have chosen to present results with heteroskedasticity-robust errors and firm fixed effects. As a robustness check, we have constructed errors in different ways. In the online appendix, we report the results from our baseline regression in six variations: heteroskedasticity-consistent errors with firm fixed effects, errors clustered at the industry group level with firm fixed effects, errors clustered at the date level (with and without firm fixed effects), and bootstrapped and clustered at two levels (time and industry). While the size of the standard errors changes a little, the coefficients on both the target factor and the path-recession 
interaction (the coefficients of interest) remained significant in every approach.

\subsection{Investigating Subsamples}

The introduction of forward-looking statements by the FOMC was a major step in the evolution of its communication practices. In table 4 , we presented the results of our baseline regression for a sample starting after the introduction of these statements. We have also run our analysis for this subsample and the results are very much in line with those presented in this paper. In the online appendix, we present some key regressions for this restricted sample and for the subsample ending at the introduction of forward-looking statements.

\subsection{Alternative Recession Indicators}

All results presented in this paper rely on the NBER recession indicator for determining downturns. As an alternative to such a recession indicator, we can use recession probabilities. Recession probabilities have the advantage of providing a finer measure of the state of the economy as opposed to the crude $0-1$ measure provide by a recession dummy. Using recession probabilities instead of the NBER recession indicator does not alter the results of this paper. We refer the interested reader to the online appendix containing the results of our baseline regression with recession probabilities (as in Chauvet and Piger 2008) instead of the NBER recession indicator.

\subsection{Scheduled vs. Unscheduled Meetings}

Throughout this paper, we have combined scheduled and unscheduled FOMC meetings. In the online appendix, we show that when we only consider scheduled or unscheduled meetings, the results remain qualitatively the same. However, it is the case that the $R^{2}$ is much higher when we only consider unscheduled meetings, emphasizing that unscheduled meetings are typically accompanied by influential monetary policy announcements. As discussed at the beginning of this paper, we chose to present results where outlier meetings were removed. Outlier meetings are typically unscheduled meetings. If we were to add these outlier meetings, our results would only be reinforced. 


\subsection{Alternative Proxies for Financial Constraints}

In the section on firm-specific effects, we have presented results with a variety of proxies for financial constraints. Some of the proxies can be constructed in a different way, or close substitutes are available. We have constructed an alternative for the cash-flow-to-net-income ratio and an alternative for the debt-to-assets ratio, and we used return on assets instead of return on equity. These alternative variables have a high correlation with their counterparts used in this paper and their use does not alter the results presented above in a meaningful way.

\section{Concluding Remarks}

In this paper, we analyzed the reaction stocks to FOMC actions and communication over the period 1994-2009. We extended the methodology proposed by Gürkaynak, Sack, and Swanson (2005) to allow for temporal and cross-sectional variation in stock responses. The results in this paper are then a natural extension to the work by Ehrmann and Fratzscher (2004) and Bernanke and Kuttner (2005). Our analysis indicates that the impact of central bank communication is very heterogenous. Cyclical industries are much more sensitive, as are individual firms facing financial constraints. At the same time, we have stressed that the impact on stocks varies over the business cycle. This finding is in line with what the finance literature has found with respect to other news such as the impact of unemployment news; see Boyd, Hu, and Jagannathan (2005).

Over the whole sample, we find that a hypothetical unanticipated cut of 25 basis points in the federal funds rate is associated with about a 1 percent increase in the average return of S\&P 500 stocks. This finding mimics the finding of Bernanke and Kuttner (2005, p. 1221). Our results on the impact of central bank communication imply that during a recession, statements inducing an upward revision of the policy path of 15 points may have a large impact on asset returns, with daily return effects of over 3.5 percent for the most cyclical stocks. By construction, both our factors were orthogonal to each other, but this does not mean that these policy levers are entirely independent. Moreover, monetary policy communication is constrained by the credibility of the policymaker. 
Our results add to the topical debate on the use of forward guidance by the FOMC and central banks in general. The methodology we have built on is currently the most influential approach. But, as stressed in Woodford (2012), the approach has its limits. We cannot disentangle why market participants expect a different path for interest rates after the release of the statement. This implies that we do not know what part of FOMC communication matters. Do stock market participants change their forecast of future economic conditions? Do stock market participants infer a change in the reaction function of the FOMC? For a given FOMC meeting, our methodology does not allow for discrimination between different scenarios. For this reason, we thought of communication in terms of its immediate effects on market expectations-Does the statement induce an upward (downward) revision of future policy? - and not so much in terms of what the policymaker explicitly communicated.

The key result of this empirical exercise is that changes in the revision of the path future policy had strong conditional effects in the sample we analyzed. A variety of checks confirmed that this finding is robust. From a policy point of view, a key question is how these results carry over to forward guidance at the zero lower bound; see Woodford (2012). We feel that the approach used here is difficult to transfer to current events in U.S. monetary policy. In 2011 and 2012, Chairman Bernanke used forward guidance repeatedly and to a much larger extent than in our sample. With FOMC commitments further into the future, we may wonder whether using an approach which is limited to handling expectations one year in the future is warranted. A related concern may be that monetary policy near the zero lower bound constitutes another regime for which one needs to control. Analyzing this promises to be an interesting venue for further research, which will become feasible as time progresses and more data become available.

\section{References}

Ammer, J., C. Vega, and J. Wongswan. 2010. "International Transmission of U.S. Monetary Policy Shocks: Evidence from Stock Prices." Journal of Money, Credit and Banking 42 (s1): 179-98. 
Andersson, M., H. Dillén, and P. Sellin. 2006. "Monetary Policy Signaling and Movements in the Term Structure of Interest Rates." Journal of Monetary Economics 53 (8): 1815-55.

Basistha, A., and A. Kurov. 2008. "Macroeconomic Cycles and the Stock Market's Reaction to Monetary Policy." Journal of Banking and Finance 32 (12): 2606-16.

Belsley, D., E. Kuh, and R. Welsh. 1980. Regression Diagnostics: Identifying Influential Data and Sources of Collinearity. New York: Wiley.

Bernanke, B., and M. Gertler. 1989. "Agency Costs, Net Worth, and Business Fluctuations." American Economic Review 79 (1): $14-31$.

Bernanke, B. S., and K. N. Kuttner. 2005. "What Explains the Stock Market's Reaction to Federal Reserve Policy?" Journal of Finance 60 (3): 1221-57.

Bernanke, B. S., and V. R. Reinhart. 2004. "Conducting Monetary Policy at Very Low Short-Term Interest Rates." American Economic Review 94 (2): 85-90.

Blinder, A. 2009. "Talking about Monetary Policy: The Virtues (and Vice?) of Central Bank Communication." BIS Working Paper No. 274.

Blinder, A. S., M. Ehrmann, M. Fratzscher, J. de Haan, and D.-J. Jansen. 2008. "Central Bank Communication and Monetary Policy: A Survey of Theory and Evidence." Journal of Economic Literature 46 (4): 910-45.

Boudoukh, J., M. Richardson, and R. F. Whitelaw. 1994. "Industry Returns and the Fisher Effect." Journal of Finance 49 (5): 1595-1615.

Boyd, J. H., J. Hu, and R. Jagannathan. 2005. "The Stock Market's Reaction to Unemployment News: Why Bad News Is Usually Good for Stocks." Journal of Finance 60 (2): 649-72.

Brand, C., D. Buncic, and J. Turunen. 2010. "The Impact of ECB Monetary Policy Decisions and Communication on the Yield Curve." Journal of the European Economic Association 8 (6): 1266-98.

Chauvet, M., and J. Piger. 2008. "A Comparison of the Real-Time Performance of Business Cycle Dating Methods." Journal of Business and Economic Statistics 26 (1): 42-49. 
Cochrane, J., and M. Piazzesi. 2002. "The Fed and Interest Rates A High-Frequency Identification." American Economic Review 92 (2): 90-95.

Cook, T., and T. Hahn. 1989. "The Effect of Changes in the Federal Funds Rate Target on Market Interest Rates in the 1970s." Journal of Monetary Economics 24 (3): 331-51.

Cragg, J. G., and S. G. Donald. 1997. "Inferring the Rank of a Matrix." Journal of Econometrics 76 (1-2): 223-50.

D'Agostino, A., and K. Whelan. 2008. "Federal Reserve Information during the Great Moderation." Journal of the European Economic Association 6 (2-3): 609-20.

D'Amico, S., and M. Farka. 2011. "The Fed and the Stock Market: An Identification Based on Intraday Futures Data." Journal of Business and Economic Statistics 29 (1): 126-37.

de Haan, J., S. Eijffinger, and S. Waller. 2005. The European Central Bank: Credibility, Transparency, and Centralization. CESifo Book Series. MIT Press.

Ehrmann, M., and M. Fratzscher. 2004. "Taking Stock: Monetary Policy Transmission to Equity Markets." Journal of Money, Credit and Banking 36 (4): 719-37.

El-Shagi, M., S. Giesen, and A. Jung. 2014. "Does the Federal Reserve Staff Still Beat Private Forecasters?" ECB Discussion Paper No. 1635.

Fama, E. F., and K. R. French. 1992. "The Cross-Section of Expected Stock Returns." Journal of Finance 47 (2): 427-65.

Fender, I., B. Hayo, and M. Neuenkirch. 2011. "Monetary Policy Spillovers and Emerging Market Credit: The Impact of Federal Reserve Communications on Sovereign CDS Spreads." MAGKS Paper on Economics No. 201139, Philipps-Universitt Marburg, Faculty of Business Administration and Economics, Department of Economics (Volkswirtschaftliche Abteilung).

Fratzscher, M. 2008a. "Communication and Exchange Rate Policy." Journal of Macroeconomics 30 (4): 1651-72.

2008b. "Oral Interventions Versus Actual Interventions in FX Markets - An Event-Study Approach." Economic Journal 118 (530): 1079-1106. 
Gelman, A., and D. K. Park. 2009. "Splitting a Predictor at the Upper Quarter or Third and the Lower Quarter or Third." American Statistician 63 (1): 1-8.

Gertler, M., and S. Gilchrist. 1994. "Monetary Policy, Business Cycles, and the Behavior of Small Manufacturing Firms." Quarterly Journal of Economics 109 (2): 309-40.

Gürkaynak, R. S., B. Sack, and E. Swanson. 2005. "Do Actions Speak Louder than Words? The Response of Asset Prices to Monetary Policy Actions and Statements." International Journal of Central Banking 1 (1): 55-93.

- 2007. "Market-Based Measures of Monetary Policy Expectations." Journal of Business and Economic Statistics 25 (2): 201-12.

Hausman, J., and J. Wongswan. 2011. "Global Asset Prices and FOMC Announcements." Journal of International Money and Finance 30 (3): 547-71.

Hayo, B., A. M. Kutan, and M. Neuenkirch. 2012. "Communication Matters: US Monetary Policy and Commodity Price Volatility." Economics Letters 117 (1): 247-49.

Hayo, B., and B. Uhlenbrock. 2000. "Industry Effects of Monetary Policy in Germany." In Regional Aspects of Monetary Policy in Europe, ed. J. von Hagen and C. J. Waller, 127-58. Boston: Kluwer.

Jansen, D.-J., and J. de Haan. 2005. "Talking Heads: The Effects of ECB Statements on the Euro-Dollar Exchange Rate." Journal of International Money and Finance 24 (2): 343-61.

_. 2007. "Were Verbal Efforts to Support the Euro Effective? A High-Frequency Analysis of ECB Statements." European Journal of Political Economy 23 (1): 245-59.

Kaplan, S. N., and L. Zingales. 1997. "Do Investment-Cash Flow Sensitivities Provide Useful Measures of Financing Constraints?" Quarterly Journal of Economics 112 (1): 169-215.

Karagedikli, O., and P. L. Siklos. 2008. "Explaining Movements in the NZ Dollar - Central Bank Communication and the Surprise Element in Monetary Policy?" Discussion Paper No. 2008/02, Reserve Bank of New Zealand. 
Kurov, A. 2010. "Investor Sentiment and the Stock Market's Reaction to Monetary Policy." Journal of Banking and Finance 34 (1): 139-49.

Kuttner, K. N. 2001. "Monetary Policy Surprises and Interest Rates: Evidence from the Fed Funds Futures Market." Journal of Monetary Economics 47 (3): 523-44.

Kwan, S. 2007. "On Forecasting Future Monetary Policy: Has Forward-Looking Language Mattered?" Economic Letter No. 2007-15 (June 15), Federal Reserve Bank of San Francisco.

Laeven, L., and H. Tong. 2012. "US Monetary Shocks and Global Stock Prices." Journal of Financial Intermediation 21 (3): 53047.

Lamont, O., C. Polk, and J. Saa-Requejo. 2001. "Financial Constraints and Stock Returns." Review of Financial Studies 14 (2): 529-54.

Lucca, D. O., and E. Moench. 2015. "The Pre-FOMC Announcement Drift." Journal of Finance 70 (1): 329-71.

Nilsen, J. H. 2002. "Trade Credit and the Bank Lending Channel." Journal of Money, Credit and Banking 34 (1): 226-53.

Peek, J., E. S. Rosengren, and G. Tootell. 2003. "Does the Federal Reserve Possess an Exploitable Informational Advantage?" Journal of Monetary Economics 50 (4): 817-39.

Peersman, G., and F. Smets. 2005. "The Industry Effects of Monetary Policy in the Euro Area." Economic Journal 115 (503): 319-42.

Perez-Quiros, G., and A. Timmermann. 2000. "Firm Size and Cyclical Variations in Stock Returns." Journal of Finance 55 (3): 1229-62.

Petersen, M. A. 2009. "Estimating Standard Errors in Finance Panel Data Sets: Comparing Approaches." Review of Financial Studies 22 (1): 435-80.

Piazzesi, M., and E. T. Swanson. 2008. "Futures Prices as RiskAdjusted Forecasts of Monetary Policy." Journal of Monetary Economics 55 (4): 677-91.

Rigobon, R., and B. Sack. 2004. "The Impact of Monetary Policy on Asset Prices." Journal of Monetary Economics 51 (8): 1553-75. 
Romer, C. D., and D. H. Romer. 2000. "Federal Reserve Information and the Behavior of Interest Rates." American Economic Review 90 (3): 429-57.

Sims, C. A. 2002. "The Role of Models and Probabilities in the Monetary Policy Process." Brookings Papers on Economic Activity 2002 (2): 1-62.

Swanson, E. T. 2006. "Have Increases in Federal Reserve Transparency Improved Private Sector Interest Rate Forecasts?" Journal of Money, Credit and Banking 38 (3): 791-819.

Thorbecke, W. 1997. "On Stock Market Returns and Monetary Policy." Journal of Finance 52 (2): 635-54.

Welsh, R., and E. Kuh. 1977. "Linear Regression Diagnostics." Technical Report No. 923-77, Sloan School of Management, Massachussetts Institute of Technology.

Wongswan, J. 2009. "The Response of Global Equity Indexes to U.S. Monetary Policy Announcements." Journal of International Money and Finance 28 (2): 344-65.

Woodford, M. 2005. "Central Bank Communication and Policy Effectiveness." In The Greenspan Era: Lessons for the Future. Proceedings of the Annual Economic Policy Symposium sponsored by the Federal Reserve Bank of Kansas City, Jackson Hole, Wyoming, August 25-27.

. 2012. "Methods of Policy Accommodation at the InterestRate Lower Bound." In The Changing Policy Landscape. Proceedings of the Annual Economic Policy Symposium sponsored by the Federal Reserve Bank of Kansas City, Jackson Hole, Wyoming, August 30-September 1.

Yellen, J. L. 2006. "Enhancing Fed Credibility." Economic Letter No. 2006-05 (March 17), Federal Reserve Bank of San Francisco. 